\title{
Polymer Brushes Tethered ZnO Crystal on Cotton Fibre and Application on Durable and Washable UV Protective Clothing
}

DOI:

10.1002/admi.201900564

\section{Document Version}

Accepted author manuscript

Link to publication record in Manchester Research Explorer

Citation for published version (APA):

Wang, X., Chen, X., Cowling, S., Wang, L., \& Liu, X. (2019). Polymer Brushes Tethered ZnO Crystal on Cotton Fibre and Application on Durable and Washable UV Protective Clothing. Advanced Materials Interfaces. https://doi.org/10.1002/admi.201900564

\section{Published in:}

Advanced Materials Interfaces

\section{Citing this paper}

Please note that where the full-text provided on Manchester Research Explorer is the Author Accepted Manuscript or Proof version this may differ from the final Published version. If citing, it is advised that you check and use the publisher's definitive version.

\section{General rights}

Copyright and moral rights for the publications made accessible in the Research Explorer are retained by the authors and/or other copyright owners and it is a condition of accessing publications that users recognise and abide by the legal requirements associated with these rights.

\section{Takedown policy}

If you believe that this document breaches copyright please refer to the University of Manchester's Takedown Procedures [http://man.ac.uk/04Y6Bo] or contact uml.scholarlycommunications@manchester.ac.uk providing relevant details, so we can investigate your claim.

\section{OPEN ACCESS}




\section{WILEY-VCH}

DOI: 10.1002/ ((please add manuscript number))

Article type: Full Paper

Title: Polymer Brushes Tethered ZnO Crystal on Cotton Fibre and Application on Durable and Washable UV Protective Clothing

Xi Wang, Xiaogang Chen, Stephen Cowling, Libo Wang, and Xuqing Liu*

Xi Wang, Dr. Xiaogang Chen, Stephen Cowling, Dr. Xuqing Liu

School of Materials, University of Manchester, Oxford Road, Manchester, M13 9PL, UK

E-mail: xuqing.liu@manchester.ac.uk

Dr. Libo Wang,

School of Materials Science and Engineering, Henan Polytechnic University, Jiaozuo, Henan, 454000, China

Keywords: polymer brush, UV protection, morphological control, $\mathrm{ZnO}$ nanocrystals

\section{Abstract}

To improve the durability and washability of ultraviolet (UV) protective fabrics, grafted polymer brushes are introduced as platforms for in-situ growth of zinc oxide ( $\mathrm{ZnO})$ nanostructure on modified cotton fibres, using the electroless deposition approach. Hollow cotton fibre acts as a micro-reactor for $\mathrm{ZnO}$ deposited on both inner and outer surfaces. More importantly, adjusting the reaction in a micro-environment enable effective control of the morphology of $\mathrm{ZnO}$ crystals and the functionalized fabric shows durable UV blocking properties. Unlike other finishing processes, the functional $\mathrm{ZnO}$ nanocrystals are grown not only on the surface of the fibres but also inside of the hollow cotton fibres but with different morphology. This unique property of the post-modification allows the functional fabrics to show good antifriction capability, washability, and durability. The combination of the zinc oxide and the textiles brings out new features for plain cloth, and the final product can be applied to outdoor clothing, protective suits, tents, and curtains, etc. 


\section{WILEY-VCH}

\section{Introduction}

People who suffer through a large amount of exposure to ultraviolet (UV) rays are at higher risk of contracting skin cancer. Lately, the damaged ozone layer has increased the health risk to all the creatures on our planet, because a more considerable amount of ultraviolet irradiation can reach the earth's surface. In general, ultraviolet is classified as electromagnetic radiation with a wavelength between $10 \mathrm{~nm}$ and $400 \mathrm{~nm}$. According to ISO standard ISO21348, UV light can be subdivided into several types: UVA wavelength ranges from $320 \mathrm{~nm}$ to $400 \mathrm{~nm}$ with UVA-2 at 320-340 $\mathrm{nm}$ and UVA-1 at 340-400 nm; UVB wavelength ranges from 290 to $320 \mathrm{~nm}$; UVC wavelength ranges from 100 to $290 \mathrm{~nm} .^{[1]}$ Among them, UVA light may not be fully absorbed by the ozone layer and can reach the corium layer to damage the elastic fibres and the rubber plateau protein, eventually aging the skin. As for UVB light, only $2 \%$ of it reaches of the earth's surface and gets to the cuticular layer of our skin. Usually, a proper amount of UVB will help mineral metabolism and formation of vitamin D, but too much UVB will cause sunburn. Moreover, under an extended period or a large amount of exposure to UV light can even cause skin cancer.

UV light comes not only from the sun, but also from portable ultraviolet lamps, gas-discharge lamps, incandescent lamps, ultraviolet LEDs, and electric arcs, which are artificial sources of UV light. UV lights from the sun and these different artificial illuminates can reach the skin and cause metabolic and biological reactions to human health in the form of various pathologies, such as tanning, skin reddening, acne, ageing, Alzheimer's disease, inflammation erythema, local or systemic immunosuppression, skin cancer, and damage to the DNA molecules of life. ${ }^{[2]}$ At the moment, one effective suggestion is wearing clothing to block the detrimental UV irradiation. ${ }^{[3-8]}$ Developing novel products to protect the human body from $\mathrm{UV}$ is one of the most significant objectives in many industries, so even with long term exposure of UV outside, the chance of free-radical-formation is minimized. ${ }^{[9-10]}$ Most clothing 


\section{WILEY-VCH}

materials, whether natural fibres, such as cotton, wool, and silk, or synthesized fibres, nylon, and PET, have limited UV-blocking properties; moreover, the clothing material itself could be decomposed by irradiating with UV rays. ${ }^{[9,11]}$ Thus, the development of effective UV shielded clothing is of considerable importance to protect our human body. ${ }^{[12]}$

Now $\mathrm{ZnO}$ has already been widely researched to be applied in solar cells, photo-diodes, sunscreens, sensors, UV absorbers, photo-catalysis and catalysts, anti-reflection coatings and electroacoustic transducers. ${ }^{[13-19]}$ Semi-conductive $\mathrm{ZnO}$ nanomaterials could be used as one of the most effective UV blocking agents, because $\mathrm{ZnO}$ is chemically stable under a high temperature environment and is non-toxic. ${ }^{[6,20-21]}$ Two main methods can be used to prepare $\mathrm{ZnO}$ crystal functional clothing: physical processes and chemical rout. ${ }^{[22-25]}$ Physical processes, such as chemical vapour deposition and physical vapour deposition, could be employed to coat $\mathrm{ZnO}$ nanostructures on the surface of fibre, but however, as there is no strong attachment between the $\mathrm{ZnO}$ and the fibres, leading to poor durability. Another limitation in physical processes is the large equipment dependence for scaling up. ${ }^{[9,26-27]}$ Thus, some chemical finishing achievements have been developed. The primary method is mixing the cross-linking agent and $\mathrm{ZnO}$ powder to enhance the washability of functional clothing. ${ }^{[28-}$ ${ }^{30]}$ However, this traditional finishing method increases the thickness of fabrics and changes the fabric handle felling properties. More importantly, the functional film coatings only cover the outer fabrics and can easily be removed during washing or daily friction. Therefore, polymer-assisted deposition for metal-oxide is a simple, feasible, high-quality method for application. ${ }^{[31-32]}$ Therefore, a strong demand exists for a universal approach toward generating effective UV shielded clothing.

Here in this report, polyelectrolyte brushes modified cotton fibers played as microreactors for in-situ growth of $\mathrm{ZnO}$ nanocrystals, to obtain a homogeneous, continuous, abundant $\mathrm{ZnO}$ crystal layer coated fabric. Pre-grafting polyelectrolyte brushes tether this as-made $\mathrm{ZnO}$ crystal layers to the fibres. The morphology of $\mathrm{ZnO}$ can be controlled by experiments and is 


\section{WILEY-VCH}

shown according to the different optical properties. Interestingly, we find that $\mathrm{ZnO}$ can deposit in the inner part of hollow cotton fibres with different morphologies.

\section{Results and Discussion}

\subsection{Characterization of $\mathrm{ZnO}$}

\subsubsection{Surface Morphology Controllability and Observation of the Role of Polyelectrolyte} Brushes

Fourier transform infrared (FTIR) was employed to investigate the successful grafting of polyelectrolyte brushes on the surface of cotton. Compared with pristine cotton, after surface grafting, FTIR result (Figure S 1b) shows a new sharp peak at $1715 \mathrm{~cm}^{-1}$, which attributed to the $-\mathrm{C}=\mathrm{O}$, and another new peak at $814.78 \mathrm{~cm}^{-1}$ attribute to $\mathrm{Cl}^{-}$, which are the main evidence of poly[2-(methacryloyloxy)ethyl-trimethylammonium chloride grafting on surface of cotton. To examine the role of grafting polyelectrolyte brushes, raw cotton fabrics, without any chemical treatment, were immersed into a $5 \mathrm{mM}$ of ammonium tetrachloropalladate(II) solution for 30 minutes and washed several times using DI water. From the observed scanning electron microscopy (SEM) image, Figure 1, only some isolated $\mathrm{ZnO}$ nanorods directly fall on the surface of cotton fibre without any adhesion force; these $\mathrm{ZnO}$ nanostructures are deduced to be from the solution precipitations. The deposition is similar to snow falling on the ground and can be easily washed away by daily washing cycles. The microstructure and macro-morphology of raw cotton of was shown in Table S 1 and Figure S 4.

\subsubsection{Morphology Control by ZnO Nanostructure Deposition Time}

Figure 2 shows the plane-view morphology of $\mathrm{ZnO}$ growth on the cotton fibre as observed by SEM, with prolonged time from 10 minutes to 1 hour at $70{ }^{\circ} \mathrm{C}$ and $90{ }^{\circ} \mathrm{C}$, respectively. The SEM results in Figure $\mathbf{2 d}$ and $\mathbf{2 h}$ show two different morphologies with two different reaction temperatures. When the temperature was $90{ }^{\circ} \mathrm{C}$ (Figure $\mathbf{2 h}$ ), the $\mathrm{ZnO}$ film formed compact amassment nanorods vertical to the substrate. It appears that $\mathrm{ZnO}$ films uniformly cover each fibre of the entire samples and are similarly; the crystallites are well-faceted with the base diameter and height of $500 \mathrm{~nm}$ and approximately $2 \mu \mathrm{m}$, respectively, and they 


\section{WILEY-VCH}

present a characteristic hexagonal prism shape. The hexagonal crystals are tightly packed, and the composition of columns has a clear interface. The grains, which are formed with many small columns and possess clear interface with one another at the beginning of the electroless deposition, are defined.

Furthermore, the grafting polymer brushes offer a stable platform to anchor the palladium catalyst for electroless deposition. To confirm this hypothesis of the formation of a small column and investigate the reaction's dynamic processes of $\mathrm{ZnO}$ electroless deposition, the morphology of samples by different deposition times were observed by SEM to determine the potential mechanism of $\mathrm{ZnO}$ growth on the polymer brushes' modified cotton surface. While the temperature was at $70{ }^{\circ} \mathrm{C}$ (Figure $2 \mathrm{~d}$ ), the morphology of $\mathrm{ZnO}$ nanorod on the surface of cotton is different with the results in $90^{\circ} \mathrm{C}$, in which $\mathrm{ZnO}$ formed compact amassment nanorods with spindle morphology. The base diameter and height of the crystallites were approximately $400 \mathrm{~nm}$ and $2 \mu \mathrm{m}$, respectively. As reaction temperature increased, the diameter of $\mathrm{ZnO}$ nanorods was enlarged, which suggests higher temperature can accelerate the growth of $\mathrm{ZnO}$ nanocrystals according to Thermodynamic control.

In Figure 2, at the beginning of the deposition, the $\mathrm{ZnO}$ nanorods did not deposit on the surface of fibre consistently. With prolonged time, crystals became more consistently and compact coated the surface. In this case, the forest-like $\mathrm{ZnO}$ can absorb more UV light. Also, the morphology of $\mathrm{ZnO}$ crystals could be controlled well by solution concentration and temperature. The proposed $\mathrm{ZnO}$ electroless deposition mechanism was illustrated as follows: ${ }^{[33]}$

$\mathrm{Zn}\left(\mathrm{NO}_{3}\right)_{2} \rightarrow \mathrm{Zn}^{2+}+2 \mathrm{NO}_{3}^{-}$

$\left(\mathrm{CH}_{3}\right)_{2} \mathrm{NHBH}_{3}+\mathrm{H}_{2} \mathrm{O} \rightarrow \mathrm{BO}_{2}^{-}+\left(\mathrm{CH}_{3}\right)_{2} \mathrm{NH}+7 \mathrm{H}^{+}+6 \mathrm{e}^{-}$

$\mathrm{NO}_{3}^{-}+\mathrm{H}_{2} \mathrm{O}+2 \mathrm{e}^{-} \rightarrow \mathrm{NO}_{2}^{-}+2 \mathrm{OH}^{-}$

$\mathrm{Zn}^{2+}+2 \mathrm{OH}^{-}+2 \mathrm{H}_{2} \mathrm{O} \rightarrow \mathrm{Zn}(\mathrm{OH})_{4}^{2-}+2 \mathrm{H}^{+}$

$\mathrm{Zn}(\mathrm{OH})_{4}{ }^{2-}+2 \mathrm{H}^{+} \rightarrow \mathrm{ZnO}+3 \mathrm{H}_{2} \mathrm{O}$ 


\section{WILEY-VCH}

As the electroless deposition process is a self-catalysis process, with prolonged process time, the deactivation of catalyst was increasing. Therefore, no further agglomeration occurred with prolonged time. After the $1 \mathrm{~h}$ deposition time, the $\mathrm{ZnO}$ nanostructure film had formed compact amassment nanorods vertical to the substrate. Because of side extrusion effect, only vertically grown $\mathrm{ZnO}$ nanorods were able to keep growing on the substrate after longtime treatment.

\subsubsection{XRD Results and Crystal Structure}

The deposited $\mathrm{ZnO}$ was structurally characterized by XRD in Figure S 3, which shows X-ray diffraction patterns of pristine cotton and $\mathrm{ZnO}$ deposited cotton. Especially, Figure 3 shows the XRD patterns of the deposited $\mathrm{ZnO}$ with the characteristic peak (100), (002) and (101). Highly crystalline $\mathrm{ZnO}$ crystals were formed by the electroless deposition method, which showed a hexagonal column structure of wurtzite-type $\mathrm{ZnO}$.

\subsubsection{TEM Results and Crystal Structure}

TEM images helped to reveal the crystal structure of $\mathrm{ZnO}$ nanorods. In Figure 4, from the image (a), it illustrates the morphology of a single $\mathrm{ZnO}$ nanorod, which length is about 100 $\mathrm{nm}$, while image (b) shows one end of a nanorod and indicates that the diameter of it is around $20 \mathrm{~nm}$. Besides, the selected-area electron microscopy diffraction (SAED) reveals the complete diffraction pattern, demonstrating the monocrystalline phase of $\mathrm{ZnO}$ on the surface of fibres, as the monocrystalline loaded will contribute to UV-blocking property. ${ }^{[34]}$

\subsection{UV management property}

\subsubsection{UV-blocking Performance}

The utilization of UV blocking performance of $\mathrm{ZnO}$ functionalized fabrics is the primary purpose of this study. "Ultraviolet protection factor" (UPF), was employed to evaluate the UV-blocking performance of the functional fabrics. Mainly, the UPF of fabric depends on various factors of fabrics, including fibre content, weave, fabric colour, finishing processes, the presence of additives, and laundering. To avoid any systematic error, woven cotton fabrics with the same parameter were employed. As the results showed, no much influence existed on 


\section{WILEY-VCH}

the UV blocking property by polymer brush grafted cotton. After grafting polymer brushes and ion exchange, the fabrics treated by $\mathrm{ZnO}$ crystals were investigated as a function of electroless deposition time. It has been confirmed that the $\mathrm{ZnO}$ crystals show smaller and continued properties, from the morphology result observed by SEM. This morphological change influences the UV blocking performance of the functional fabric: longer deposition time, and better UPF value. The UPF of more than 350 has been achieved when the deposition of 3 h was used, shown in Figure 5. The washing speed was performed according to the AATCC Test Method 61-1996 test No. 2A. The decay of UPF is mainly due to the friction between the fibres. However, exist of polymer brush improved the bonding between fibres substrate and $\mathrm{ZnO}$ nanocrystals. Therefore, the value of UPF decreased after 5-washing cycles in the beginning but remained a relatively high level after even 50-washing process, as $\mathrm{ZnO}$ nanocrystals were always showed on the fibres. Also $\mathrm{ZnO}$ loaded on the inner wall of fibres would contribute to good washability property. To indicate the protection performance of modified cotton fabrics from UV, transitivity of UV of different deposited times were investigated, and the unmodified cotton was also tested as a control sample. From the curve in

Figure 6, complete wavelength blocking can be observed for the UV range of 280-400. The potential mechanism of the SPF activity is attributed to the electronic structure of the deposited $\mathrm{ZnO}$ semiconductors. The as-prepared products can absorb light with energy of hv that matches or exceeds their band gap energy (Eg). Comparing with other research, ${ }^{[35-37]}$ the UV blocking property is much better, especially at the wavelength from 280 to $350 \mathrm{~nm}$.

\subsubsection{Washing Fitness of UV-blocking Fabrics}

One of the central expected preponderance of polymer brushes bridged functional nanorods is the washing fitness. Following the test standard from the Technic Manual of the AATCC, the performance of washing fitness was investigated. The washing cycle 5, 10, 15, 20, 30, 40, and 50 were selected, and the UV blocking performances of each sample were tested. From Figure 7, after five washing cycles, the UPF value sharply decreased because the $\mathrm{ZnO}$ 


\section{WILEY-VCH}

nanocrystals on the outer surface were quickly washed away because of the friction force during washing. Moreover, nanoflake- $\mathrm{ZnO}$ was grown on the inside wall of fibres, while nanorod-ZnO was loaded on the outer wall. When the washing cycles increased, the UPF slightly decreased. This good washing speed is attributed to the $\mathrm{ZnO}$ nanostructure growth in the inner of the fibre, as shown in Figure 8, and the unique structure could not be removed by friction force during washing. Comparing with pristine cotton structure (Figure S 4), there were $\mathrm{ZnO}$ structure in the lumen of cotton fibres even after 20 washing cycles.

\section{Conclusion}

To enhance the interaction between the $\mathrm{ZnO}$ nanorods and the cotton textile, polyelectrolyte brushes acting as a supporting catalyst system for electroless deposition of $\mathrm{ZnO}$ nanorod were developed in this study. The deposition was carried out on cotton fabrics at different deposition time points to form vertically grown $\mathrm{ZnO}$ nanocrystals on fibre surface, which morphology was co-regulated by thermodynamics and kinetics during reaction process. Morphological analysis reveals that the process leads to the formation of monocrystalstructure $\mathrm{ZnO}$, which have good UV blocking property, proved by UV protection factor. Compared with other techniques, this process has largely improved the wash durability of UV blocking fabrics, due to exist of $\mathrm{ZnO}$ at the inner wall of fibres (proved by SEM) and the polymer-tethered structure. The internal growth of $\mathrm{ZnO}$ has provided a new pathway to improve UV blocking property.

\section{Experimental Section}

Experimental materials:[2-(Methacryloyloxy)ethyl]trimethylammonium chloride (METAC), 3-(trichlorosilyl)propyl 2-bromo-2-methylpropanoate, toluene, methanol, ammonium tetrachloropalladate(II), zinc nitrate hexahydrate and dimethylamineborane complex $\left[\left(\mathrm{CH}_{3}\right)_{2} \mathrm{NHBH}_{3}\right]$ were purchased from Sigma-Aldrich, Inc. All the chemicals were analytic grade and used without further purification. initiator 3-(trichlorosilyl)propyl 2-bromo-2- 


\section{WILEY-VCH}

methylpropanoate was synthesized in our lab. Cotton fabric was obtained from the dyeing lab of University of Manchester.

Sample fabrication: The process of fabricating metal oxide nanostructure-polymer brush fibres is schematically illustrated in Scheme 1. The poly[2-(methacryloyloxy)ethyltrimethylammonium chloride] (PMETAC) brush grafted cotton was synthesized by surfaceinitiated atomic transfer radical polymerization (ATRP). Firstly, cotton was immersed into the $10 \mathrm{mM}$ 3-(trichlorosilyl)propyl 2-bromo-2-methylpropanoate for 10 hours, which can react with hydroxyl of cotton in order to form silicon-oxygen covalent bond directly. Then to remove any physisorbed initiator on the surface, the initiator-grafted samples were rinsed by anhydrous toluene for three times. Subsequently, the initiator 3-(trichlorosilyl)propyl 2bromo-2-methylpropanoate tethered cotton was sealed in Schlenk tubes and degassed with $4 \times$ high-vacuum pump/ $\mathrm{N}_{2}$ refill cycles. Then the sample was immersed by prepared polymerization solution (the preparation method was stated in SI) in Schlenk tube at $60{ }^{\circ} \mathrm{C}$ for 10 hours degassed by passing a continuous stream of dry $\mathrm{N}_{2}$ through the solution to produce polymer brush from cotton surface. The specimen was cleaned with methanol and distilled water for several times and dried in $\mathrm{N}_{2}$. Then, the modified cotton fabrics were immersed into $5 \mathrm{mM}$ of ammonium tetrachloropalladate(II) solution for $30 \mathrm{mins}$ and rinsed in distilled water. Then the pretreated substrates were immersed into aqueous solution at $70{ }^{\circ} \mathrm{C}$ and $90{ }^{\circ} \mathrm{C}$, which contained $0.05 \mathrm{M}$ zinc nitrate hexahydrate and $0.05 \mathrm{M}$ dimethylamineborane complex $\left[\left(\mathrm{CH}_{3}\right)_{2} \mathrm{NHBH}_{3}\right]$. The substrates were immersed in the prepared solution for $1 \mathrm{~min}$ to $2 \mathrm{hrs}$ for $\mathrm{ZnO}$ thin film growth. During the deposition, Ar gas was passed over slightly into the free space of the vessel. The deposited cotton fabrics were rinsed with deionized water (DI-water) and dried under the ambient atmosphere.

\section{Characterization:}

Fourier transform infrared (FTIR) spectrometry (Bruker Hyperion 3000 IR microscope) was employed to identify the functional groups on pristine cotton and polymer brush cotton to 


\section{WILEY-VCH}

evaluate the surface modification of polymerization. FTIR data were collected for pure cotton and polymer brush cotton composites for wavenumbers $550-4000 \mathrm{~cm}^{-1}$. The crystal structure of functional fabrics was characterized by powder X-ray diffraction (XRD, Philips X 'pert diffract meter in $\theta-2 \theta$ configuration). The morphologies were observed using field emission scanning electron microscopy (Leica Stereo-scan 440, operating at $20 \mathrm{kV}$; JSM-6335F at 3.0 $\mathrm{kV}$, JEOL, Tokyo, Japan). Thermo gravimetric analysis (TGA) and differential scanning calorimeter (DSC) were tested by Perkin-Elmer DSC7 system at Air/N2 ambient condition. The lattice space was investigated using high-resolution transmission electron microscopy (JEOL JEM 2010 operated at $200 \mathrm{kV}$ ). The ultraviolet protection factor (UPF) of fabrics was evaluated by a Varian Cary 300 UV spectrophotometer with the aid of the cotton fabrics as substrates according to the Australian/New Zealand Standard AS/NZS 4399:1996. Washability performance was investigated with reference to the Technic Manual of the American Association of Textile Chemists and Colorists (AATCC). Washing tests were performed using laundering machine (AATCC Standard Instrumental Atlas Launder-Ometer LEF, Atlas electric devices company, Chicago, IL, USA) at $49{ }^{\circ} \mathrm{C}$ in a $1.2 \mathrm{~L}$ stainless steel lever lock canister.

\section{Supporting Information}

Supporting Information is available from the Wiley Online Library or from the author.

\section{Acknowledgements}

We would like to thank the support of the EU Horizon 2020 and University of Manchester through projects with project codes 644268-ETEXWELD-H2020-MSCA-RISE-2014, AA14512 (UMRI project "Graphene-Smart Textiles E-Healthcare Network") and the British Cotton Growing Association Work People's Collection Fund for funding the project "Protective Efficiency of Respiratory Protective Equipment (RPE) against Byssinosis for Cotton Workers"'. 


\section{WILEY-VCH}

\section{References}

[1] Sadeghifar, H.; Venditti, R.; Jur, J.; Gorga, R. E.; Pawlak, J. J., Acs Sustainable Chemistry \& Engineering 2017, 5, 625-631.

[2] El.Shafei, A.; Abou-Okeil, A., Carbohydrate Polymers 2011, 83, 920-925.

[3] Wang, R.; Xin, J.; Tao, X., Inorganic chemistry 2005, 44, 3926-3930.

[4] Xin, J.; Daoud, W.; Kong, Y., Textile Research Journal 2004, 74, 97-100.

[5] Mao, Z.; Shi, Q.; Zhang, L.; Cao, H., Thin Solid Films 2009, 517, 2681-2686.

[6] Yadav, A.; Prasad, V.; Kathe, A.; Raj, S.; Yadav, D.; Sundaramoorthy, C.;

Vigneshwaran, N., Bulletin of Materials Science 2006, 29, 641-645.

[7] Lu, H.; Fei, B.; Xin, J. H.; Wang, R.; Li, L., Journal of colloid and interface science 2006, 300, 111-116.

[8] Wang, L.; Zhang, X.; Li, B.; Sun, P.; Yang, J.; Xu, H.; Liu, Y., Acs Applied Materials \& Interfaces 2011, 3, 1277-1281.

[9] Kathirvelu, S.; D’souza, L.; Dhurai, B., Indian J Fibre Text Res 2009, 34, 267-273.

[10] Ghamsari, M. S.; Alamdari, S.; Han, W.; Park, H.-H., International journal of nanomedicine 2017, 12, 207.

[11] Frunza, L.; Preda, N.; Matei, E.; Frunza, S.; Ganea, C. P.; Vlaicu, A. M.; Diamandescu, L.; Dorogan, A., Journal of Polymer Science Part B: Polymer Physics 2013, 51, 1427-1437.

[12] Mazzocchetti, L.; Cortecchia, E.; Scandola, M., Acs Applied Materials \& Interfaces 2009, 1, 726-734.

[13] Becheri, A.; Dürr, M.; Nostro, P. L.; Baglioni, P., Journal of Nanoparticle Research 2008, 10, 679-689.

[14] Liao, S.-H.; Jhuo, H.-J.; Yeh, P.-N.; Cheng, Y.-S.; Li, Y.-L.; Lee, Y.-H.; Sharma, S.; Chen, S.-A., Scientific reports 2014, 4, 6813.

[15] Zhang, T.-F.; Wu, G.-A.; Wang, J.-Z.; Yu, Y.-Q.; Zhang, D.-Y.; Wang, D.-D.; Jiang, J.-B.; Wang, J.-M.; Luo, L.-B., Nanophotonics 2017, 6, 1073-1081. 


\section{WILEY-VCH}

[16] Hatamie, A.; Khan, A.; Golabi, M.; Turner, A. P.; Beni, V.; Mak, W. C.;

Sadollahkhani, A.; Alnoor, H.; Zargar, B.; Bano, S., Langmuir 2015, 31, 10913-10921.

[17] Goh, E.; Xu, X.; McCormick, P., Scripta Materialia 2014, 78, 49-52.

[18] Lee, K. M.; Lai, C. W.; Ngai, K. S.; Juan, J. C., Water research 2016, 88, 428-448.

[19] Tuico, A.; Ferrolino, J. P.; Catindig, G. A.; Tingzon, P. M.; Copa, V.; Prieto, E. A.;

Estacio, E.; Salvador, A.; Somintac, A., Proceedings of the Samahang Pisika ng Pilipinas 2015.

[20] Martins, N. C.; Freire, C. S.; Neto, C. P.; Silvestre, A. J.; Causio, J.; Baldi, G.;

Sadocco, P.; Trindade, T., Colloids and Surfaces A: Physicochemical and Engineering Aspects 2013, 417, 111-119.

[21] Li, Y.; Hou, Y.; Zou, Y., Fibers and Polymers 2012, 13, 185-190.

[22] Athauda, T. J.; Hari, P.; Ozer, R. R., ACS applied materials \& interfaces 2013, 5, 6237-6246.

[23] Guo, Z.; Chen, X.; Li, J.; Liu, J.-H.; Huang, X.-J., Langmuir 2011, 27, 6193-6200.

[24] Thi, V. H. T.; Lee, B.-K., Journal of Photochemistry and Photobiology A: Chemistry $2017,338,13-22$.

[25] Butola, B.; Garg, A.; Garg, A.; Chauhan, I., Journal of The Institution of Engineers (India): Series E 2018, 1-8.

[26] Uğur, Ş. S.; Sarışı1k, M.; Aktaş, A. H.; Uçar, M. Ç.; Erden, E., Nanoscale research letters $2010,5,1204-1210$.

[27] Li, Y.; Zou, Y.; Hou, Y., Cellulose 2011, 18, 1643-1649.

[28] El-Hady, M. A.; Farouk, A.; Sharaf, S., Carbohydrate polymers 2013, 92, 400-406.

[29] Shih, M.-K.; Wang, C.; Chen, C.-C.; Chen, J.-C.; Yao, W.-H.; Yeh, J.-T., Textile research journal 2004, 74, 1055-1060.

[30] Gull, N.; Khan, S. M.; Munawar, M. A.; Shafiq, M.; Anjum, F.; Butt, M. T. Z.; Jamil, T., Materials \& Design 2015, 67, 313-317. 


\section{WILEY-VCH}

[31] Jia, Q.; McCleskey, T. M.; Burrell, A.; Lin, Y.; Collis, G.; Wang, H.; Li, A.; Foltyn, S. J. N. m., 2004, 3, 529.

[32] Yu, Y.; Yan, C.; Zheng, Z. J. A. m., 2014, 26, 5508-5516.

[33] Boehme, M.; Ensinger, W. J. I. T. o. N., 2011, 10, 63-69.

[34] Perriere, J.; Millon, E.; Craciun, V. J. P. L. D. o. T. F. A.-L. G. o. F. M., 2007, 261.

[35] Yazhini, K. B.; Prabu, H. G. J. R. A., 2015, 5, 49062-49069.

[36] Ghamsari, M. S.; Alamdari, S.; Han, W.; Park, H.-H., International journal of nanomedicine 2017, 12, 207.

[37] Shaheen, T. I.; El-Naggar, M. E.; Abdelgawad, A. M.; Hebeish, A. J. I. j. o. b. m., 2016, 83, 426-432. 


\section{WILEY-VCH}
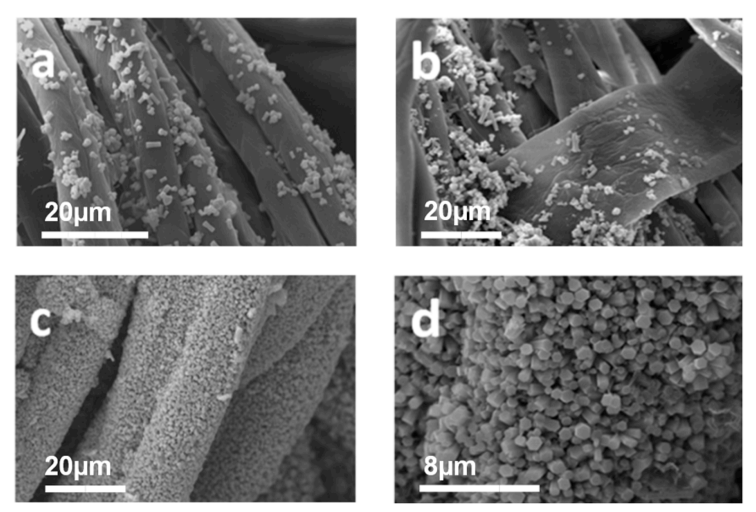

Figure 1. SEM images of $\mathrm{ZnO}$ deposition on raw cotton fabrics $(\mathrm{a}, \mathrm{b})$ and on polymer brushes modified cotton $(\mathrm{c}, \mathrm{d})$.
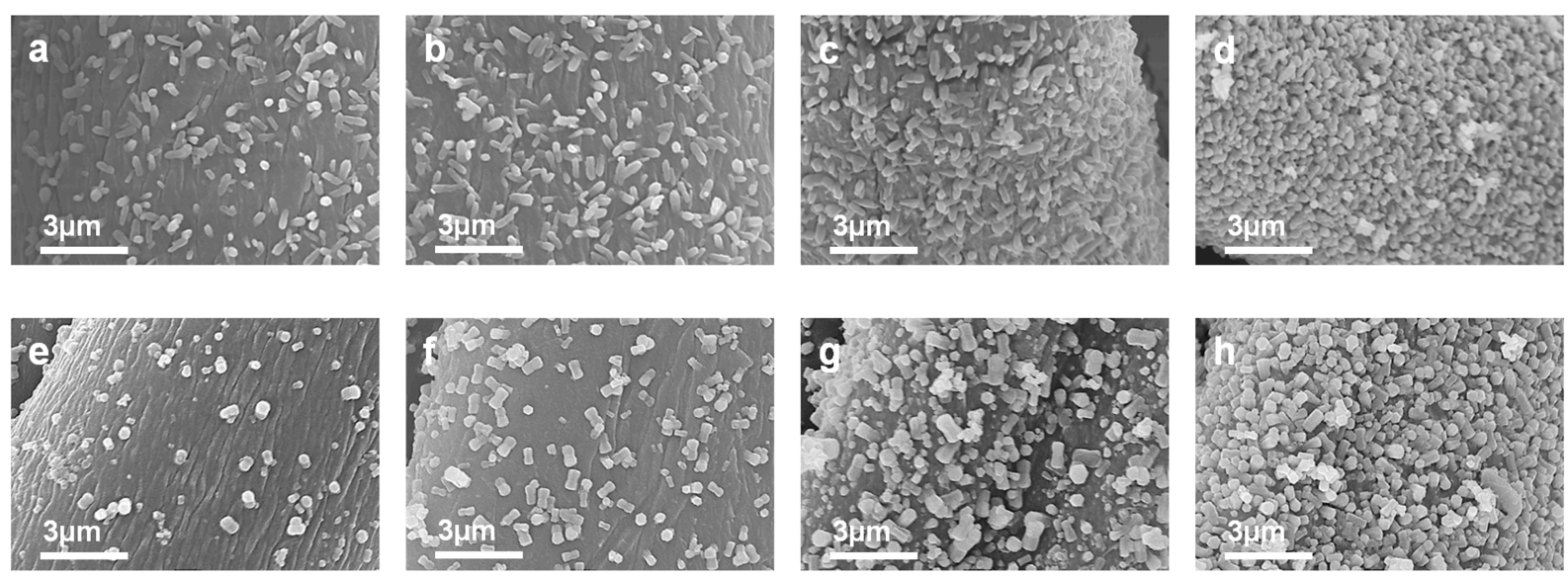

Figure 2. SEM image of low and high magnification of the $\mathrm{ZnO}$ nanorods. Surface morphology observations of $\mathrm{ZnO}$ growth on the cotton fibre by SEM, with prolonged time at $70{ }^{\circ} \mathrm{C}$ for (a) $10 \mathrm{mins}$, (b) $20 \mathrm{mins}$, (c) $40 \mathrm{mins}$ and (d) 1 hour, and at $90{ }^{\circ} \mathrm{C}$ for (e) $10 \mathrm{mins}$, (f) 20 mins, (g) 40 mins and (h) 1 hour, respectively.

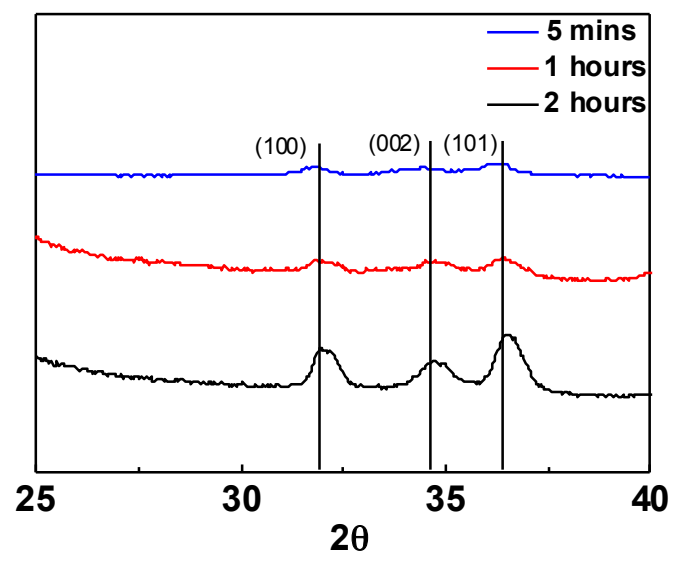

Figure 3. X-ray diffraction patterns of the deposited $\mathrm{ZnO}$ on cotton, and the deposition time is 5 mins, 1 hour and 2 hours. 


\section{WILEY-VCH}
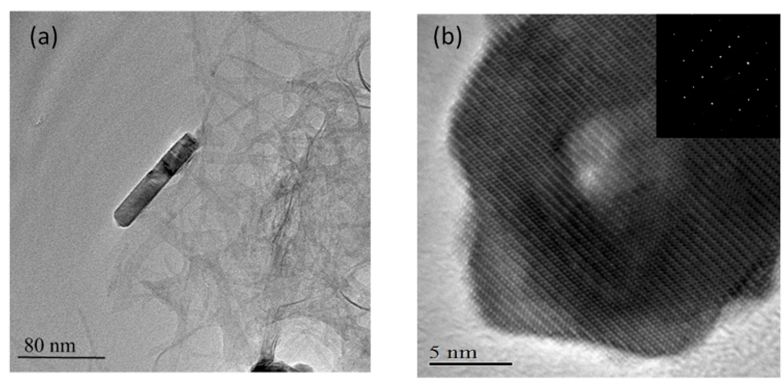

Figure 4. TEM image of low and high magnification of the $\mathrm{ZnO}$ nanorods. (a) Low magnification TEM image of a single $\mathrm{ZnO}$ nanorod. (b) High magnification TEM image of one end of $\mathrm{ZnO}$ nanorod, with diameter around $20 \mathrm{~nm}$. The inset image shows a SAED pattern taken on different single $\mathrm{ZnO}$ nanorods, indicating the crystalline phase structure of the nanorods.

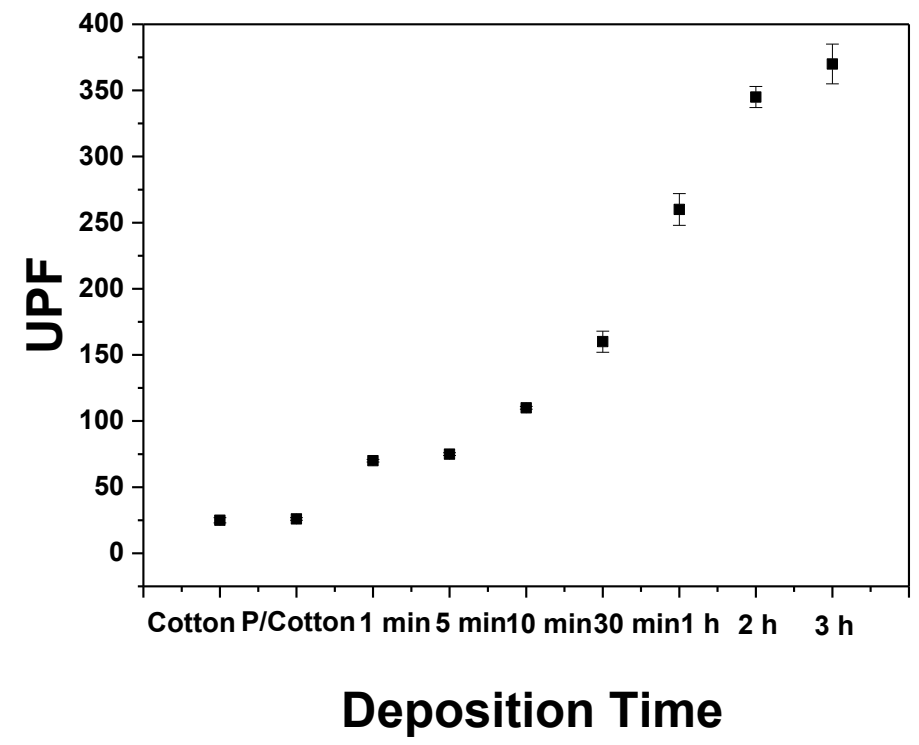

Figure 5. UV protection effectiveness of textiles according to AS/NZ standard. 


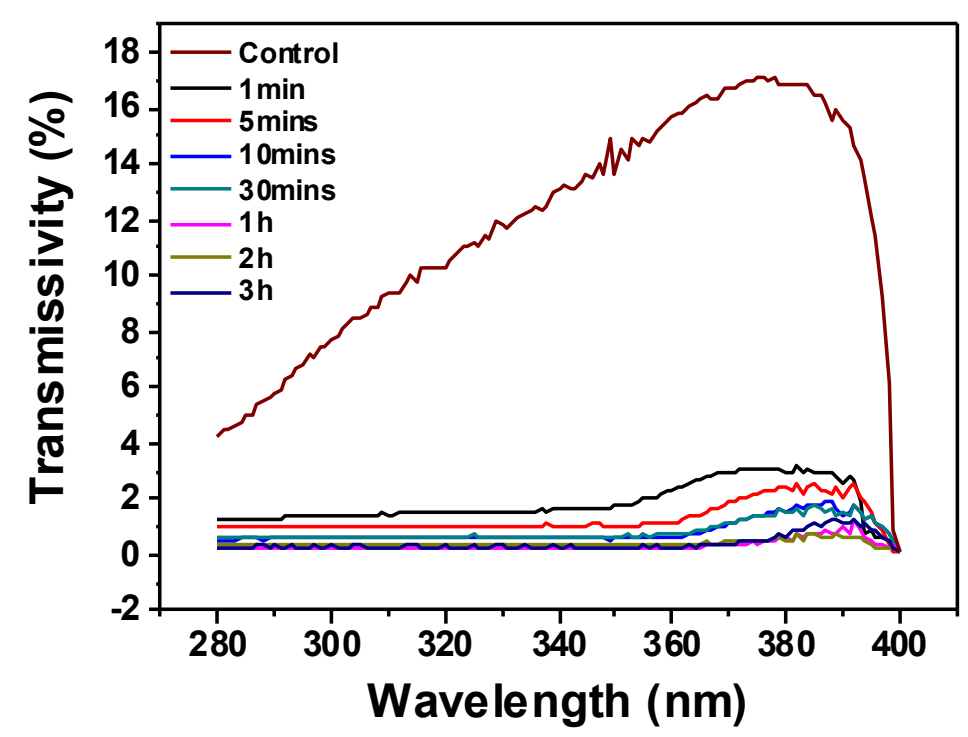

Figure 6. UV-Vis transmissivity spectra of $\mathrm{ZnO}$ deposited cotton fabrics and unmodified cotton fabrics as control sample.

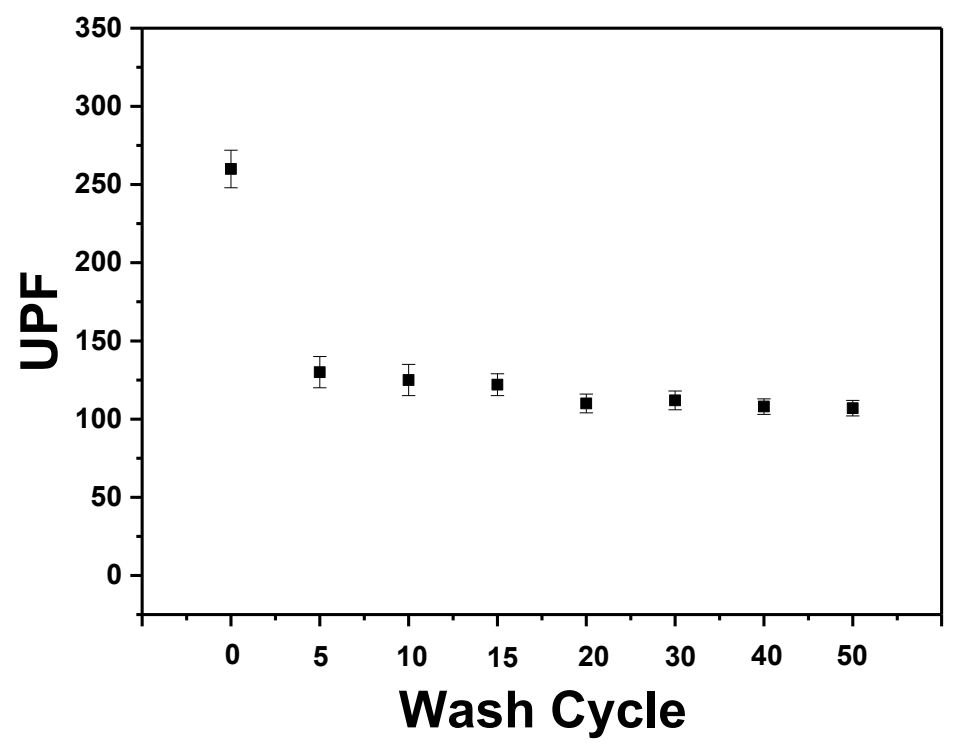

Figure 7. Wash fastness test of UV blocking functional fabrics. 


\section{WILEY-VCH}
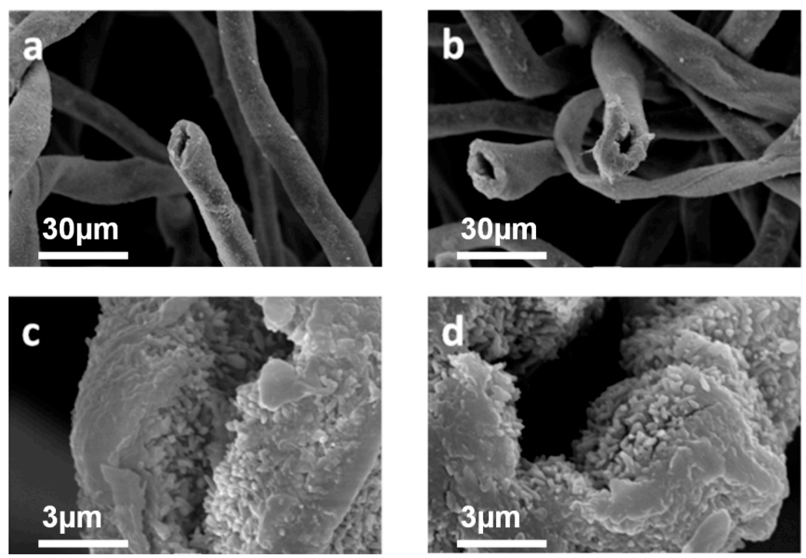

Figure 8. SEM images of cotton fabrics functionalized with $\mathrm{ZnO}$ nanorods after washing for 10 cycles $(a, c)$ and 20 cycles $(b, d)$.

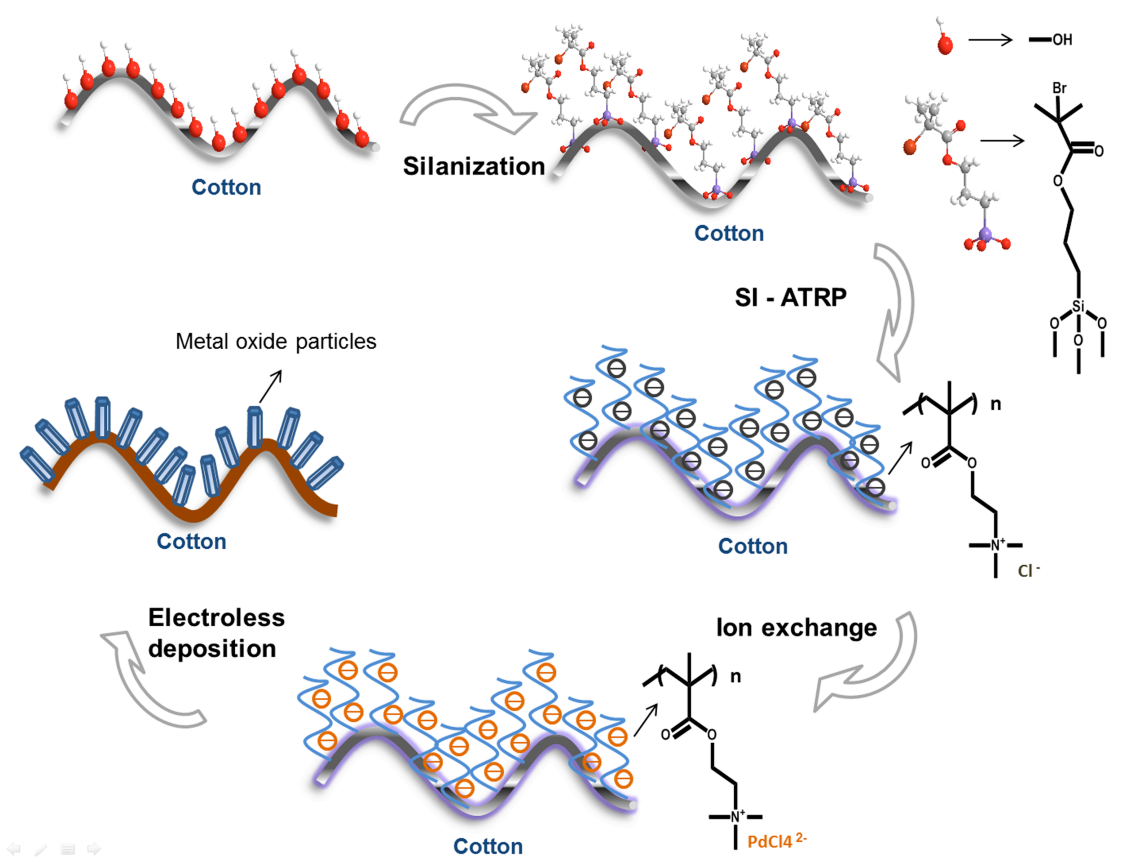

Scheme 1. Schematic illustration of the process of fabricating metal oxide nanostructurepolymer brushes-fibres hierarchical structures. 